\title{
The role of a multimedia textbook in the priority national project "education"
}

\author{
Elena Vasilenko and Pavel Vasilenko
}

Federal State Budget Education Institution of Higher Education "K. G. Razymovsky Moscow State University of technology and management (the First Cossack University)"

\begin{abstract}
In the article, the authors consider the role of a multimedia textbook in modern education. The priority national project "Education" is being implemented in Russia - the creation and implementation of modern electronic textbooks is one of the priority concepts in this project. Electronic publications enhance interactive features such as modeling, surveys, discussions, and additional multimedia materials. Advantages of electronic textbooks: mobility, large capacity of information; the ability to constantly update content, without purchasing a new textbook and financial expenses; level of visibility: you can only put text, illustrations, diagrams and graphs in a printed publication, but you can also put animation in an electronic publication, which is convenient for visual display of academic subjects. The electronic textbook provides more opportunities for learning within the existing programs, as well as for the development and optimization of the educational process.
\end{abstract}

\section{Introduction}

Such a grandiose decision and long-term event called "priority national projects" was made by Russian President Vladimir Putin. One of the aspects of implementation is the development of science and education. The priority national project "Education" is being implemented in Russia and is making great strides towards the development of the education process. The purpose of the national Russian project "Education": Ensuring global competitiveness of education in Russia, entering the Russian Federation among the 10 leading countries in quality of education. Education of a harmoniously developed and socially responsible person based on the spiritual and moral values of the peoples of the Russian Federation, historical and national cultural traditions [1].

The modern education system is now rapidly applying information technology. At the moment, distance learning is developing, in which the presence of a school student or a student in the classroom is constantly becoming optional. an electronic textbook can significantly improve the quality of the educational process. One of the priority areas in education is the use of a multimedia textbook. "Foreign and domestic scientists in their scientific works emphasize that the success of a modern person is determined by a certain degree of modern approach to professional education» [2, p.31].

The electronic textbook can be used both for self-education purposes and as part of distance learning. The development of an electronic multimedia textbook is particularly relevant in modern education. Creating such a version of the textbook will allow you to 
study all the issues presented in the textbook more widely, and will increase the efficiency, quality, and availability of educational resources for studying the discipline [3].

The first electronic textbooks appeared in 1971. The history of this method for obtaining educational information began when there was no Internet, there were no personal computers and phones.

University of Illinois student Michael HART, with access to the University computer, decided to do something useful. He believed that in the near future the computer will be available to everyone and there will be a need to translate into electronic format 10 thousand of the most famous works of world literature. The first electronic text was the American Declaration of independence, which HART carried in a backpack. The student named his initiative "Project Guttenberg" in honor of the famous first printer.

The project gained popularity and began to expand. Until 1989, texts were typed manually, then scanners and text recognition programs were used. To this day, Project Guttenberg exists as a non-profit organization [4].

In Russia, in 1994, programmer Maxim Mashkov created an online library lib.ru. It is updated mainly by users ' efforts. The library is growing and remains popular.

To date, many online libraries have appeared in the electronic space, providing books in various formats and on various topics. The need for electronic educational materials in accordance with training programs at different levels of training and in different subjects and areas remains relevant and in demand in the future of modern education. Multimedia, electronic textbook will provide ample opportunities for the development and optimization of education.

\section{Materials and Methods}

Due to the diversity of the topic, it is necessary to apply certain methods to solve the problem of identifying the features of the formation of a multimedia textbook and its role in modern education:

- collect material on the topic of creating a multimedia textbook;

- learn (analogs) - the role of interactive textbooks, their advantages and functions;

- analyze the main features of promising electronic textbooks;

- identify the characteristics of various electronic textbook carriers;

- analyze the needs for additional functionality of electronic textbooks;

- identify the main features of creating interactive textbooks;

- synthesize the advantages of a printed textbook and multimedia components.

\section{Results and Discussion}

In the modern world, schoolchildren and students are increasingly interested in everything that is somehow connected with computer and digital technologies. Young people are used to spending a lot of time on the computer and phone, and a fairly large percentage prefer to learn something new when viewing Internet articles and videos on a topic of interest. For this reason, it is necessary to fill the textbook with videos, hyperlinks to educational sources with a large amount of illustrative material, which is not possible in a printed publication [5].

Studying foreign and domestic experience, we can highlight that now most often the teacher does not act as a distributor of information, but as a consultant, coordinator, adviser, sometimes even a colleague of the student. This gives some positive aspects: students and students actively participate in the learning process, learn to think independently, put forward their point of view. 
Increasing web capabilities have ushered in a new era of reading. Some e-textbooks resemble a regular printed textbook, in which the content focuses on the academic discipline, divided into relevant chapters. While other electronic publications enhance interactive features, such as modeling, survey, discussions, and additional multimedia materials. These features are designed to help students learn by improving content in a variety of ways.

Methods of the educational process are being improved all over the world and are increasingly using new methods and techniques in the pedagogical process. The creation and implementation of a modern multimedia textbook has found wide application in many countries. Software and methodological complex, collected in one manual various educational material using the latest technologies - a modern electronic textbook, the role of which is to raise the level of the educational process to a new, higher level, adapted to the current level of the technical process and demand among the modern generation. The main characteristic of submitting educational material in this format is the ability to independently master the course or its section at the level of knowledge and skills $[6,7]$.

Multimedia technologies in an electronic textbook are a modern educational tool that combines all the advantages of various technologies that facilitate the perception of educational material and make it more accessible.

The main principles and technical features in the development of an electronic textbook are:

1. Identification of the priority pedagogical approach-designation of the goal, development of the content of the educational process. Didactic principles.

2. Organization and modular division of educational material.

3. Competent filling of each module, according to the content of the textbook. The components of the module are the theoretical part, control questions, examples, exercises for independent work, control tasks, and evaluation tools.

4. Selection of illustrative material for more accessible development of educational material, additional visual explanation, systematization and generalization of the acquired knowledge. Video materials or illustrations must contain explanations and comments to focus the student's attention on certain points in the image.

5. Special attention is paid to the variability and adaptability of the electronic textbook. Taking into account the capabilities and needs of a particular user in the learning process, the variability of the complexity of the material being studied. Graphical and geometric interpretations of the concepts studied and the solutions of problems received by the student.

The direct target audience of the designed product is schoolchildren, College students, and University students, but this does not mean that the audience is limited to this contingent. Very often, people who are interested in any science and are at the initial stage of its training resort to textbooks on their own, because it is in them that everything is described most clearly [8].

There are a number of advantages of electronic textbooks: mobility, huge volumes of encyclopedias can fit in your pocket via a mobile phone and allows you to study not only at home, but in any other place. The ability to constantly update the content, when new information on a particular issue appears, just update the textbook version without making new financial expenses is an undeniable advantage. The level of clarity, a multimedia textbook, a printed edition it is possible to put only text, illustrations, diagrams and graphs, and electronic animation, which is useful for visual display of chemical, charts, videos, which may be a fragment of informative movie, and more [9].

Considering these advantages, we can say that the electronic textbook differs from the classic paper one in that it provides significantly more opportunities for learning within the 
framework of existing programs, as well as for the development and optimization of the educational process $[10,11]$.

The publication of an electronic textbook faces the problem of delivering a large amount of text information and visual material to students on all pages, which is characterized by the presence of buttons and active links to multimedia content, free layout, and different layout of illustrations.

When developing an electronic textbook, the following computer programs are used: Adobe Photoshop, Adobe InDesign, Adobe Acrobat, Adobe Premiere Pro, Adobe Illustrator, Microsoft Word 2007, Microsoft PowerPoint, Adobe Reader [12].

Work on the project for the development and formation of a multimedia textbook includes:

- development of the project concept;

$\circ$ analysis of available publications;

- setting goals and objectives;

- format selection;

o working with data-selecting the published text;

o search for additional educational content;

o selection of thematic illustrative material;

o database for multimedia publications;

o creating and programming multimedia buttons;

$\circ$ editing and processing of video materials;

$\circ$ editing and preparing images for layout;

o layout of the publication

○ layout of text blocks;

o layout of illustrations;

$\circ$ presentation materials.

\section{Conclusions}

Popularization of electronic textbooks is one of the progressive directions in the organization of the pedagogical process of modern education. Electronic textbooks have a number of properties that will be in demand for a long period of development of electronic educational technologies. An electronic textbook based on e-book readers is as close as possible to a paper textbook, which significantly facilitates the adaptation of teachers and students to new technologies and, if necessary, allows them to conduct classes in the classroom or in the classroom, when some students use electronic textbooks, while others use traditional paper ones [13].

The advantages of an electronic textbook are also that they are much cheaper than printed ones. The introduction of electronic textbooks - technical progress in the educational environment is inevitable, as inevitable as the appearance of printed textbooks (books) in the XV century.

The wide dissemination and use of electronic textbooks, electronic educational content and distance learning technologies in the educational process will allow you to reorient General and professional education from simple memorization of encyclopedic knowledge from various fields to mastering the fundamental skills of communication, analysis, understanding and decision-making in unusual situations. 


\section{References}

1. Yu.V. Daskova, Ia.V. Poliakova, S.A. Vasilenko, O.S. Goltseva, K.N. Shevalie, E.V. Vasilenko, 8 (2020)

2. E.V. Vasilenko, P.G.Vasilenko, (2020)

3. A. Efremov, Digital photography and Photoshop (2009)

4. A. M. Kabanov, Electronic textbook as a means of improving the quality of foreign language teaching at a technical University, www.superinf.ru

5. A.V. Moshchenko, Information and communication technologies in education (2004)

6. N. A. Shigina, I. V. Kabakova, Classification of components of a multimedia electronic textbook, 4 (2001)

7. A. Written, This is what interactive textbooks of the future look like: textbook, www.computerra.ru (2003)

8. S.V. Agaponov, et al. Distance learning tools. Methodology, technology, and tools (1994)

9. S.A. Zinchenko, Introduction to the basics of the art of the Aegean world: textbook (2015)

10. 1C: Education 4.1. School 2.0, http://obr.1c.ru,

11. R. Abdulaeva, M. Gereeva, V. Bikbulatova, R. Rabadanova, G. Yulina, 40 (2017)

12. E.E. Bukhteeva, O.A. Zimovina, S.E. Shishov, R.S. Rabadanova, I.V. Polozhentseva, 20 (2019)

13. L.Zh. Karavanova, S.E. Shishov, T.M. Rozhnova, K.S. Rozhnova, I.V. Polozhentseva, L.P. Lobacheva, 2 (2020) 